\title{
Optimization of welded conical shells for axial compression and bending
}

\author{
Károly Jármai ${ }^{1}$, József Farkas², \\ ${ }^{1,2}$ University of Miskolc, H-3515 Miskolc, Hungary \\ ${ }^{1}$ Professor, Dr.sci.techn. altjar@uni-miskolc.hu, \\ ${ }^{2}$ Professor emeritus, Dr.sci.techn. altfar@uni-miskolc.hu
}

\begin{abstract}
:
The problem is to find the optimum dimensions of a cantilever column loaded by compression and bending. The column is constructed as circular or conical unstiffened shell. In both cases the cost minimum is not limited by a fabrication constraint, by which the minimum shell radius would be prescribed. The cost comparison of both structural versions shows the most economic one.
\end{abstract}

Keywords: minimum cost design, conical shell, economy of welded structures

\section{Introduction}

Columns or towers are used in many engineering structures, e.g. in buildings, wind turbine towers, piers of motorways, etc. They can be constructed as rectangular boxes or shells. Walls of boxes can be designed from stiffened plates or cellular plates. Shells can be unstiffened or stiffened circular or conical. A ring-stiffened conical shell is treated for external pressure in the case of equidistant stiffening (Farkas and Jármai 2008a) and with non-equidistant stiffening (2008b). 
Previous studies have shown that, when the constraint on horizontal displacement of the column top is not active, the unstiffened circular shell can be cheaper than that of stringer stiffened one. In the present study the unstiffened circular shell is compared to the slightly conical one to show the economy of conical shells over the circular ones.

In previous studies the fabrication has been realized by using $3 \mathrm{~m}$ long plate elements to form unstiffened shell elements. In the present study $1.5 \mathrm{~m}$ wide plate elements are used. Therefore, the shell thicknesses can be varied in more shell parts. With equidistant shell elements of the same thickness the fabrication can be realized more easily.

The optimal thickness for each shell element is calculated from the shell buckling constraint according to the Det Norske Veritas (2002) design rules.

In the previous studies the fabrication sequence is designed so that the circumferential welds have been realized for the completely assembled shell. In order to ease the welding inside the shell the fabrication is changed and it is supposed that these welds are welded successively. Thus the next $1.5 \mathrm{~m}$ wide shell part is welded to the previous longer structure and so the number of assembled parts is always 2 .

Firstly, the conical shell is optimized by using different radii with a constant inclination angle. Secondly, this angle is changed to show its effect. Thirdly, the optimal circular shell radius is sought to minimize the cost.

\section{Constraint on conical shell buckling}

According to the DNV rules (2002) the buckling of conical shells is treated like buckling of an equivalent circular cylindrical shell. 


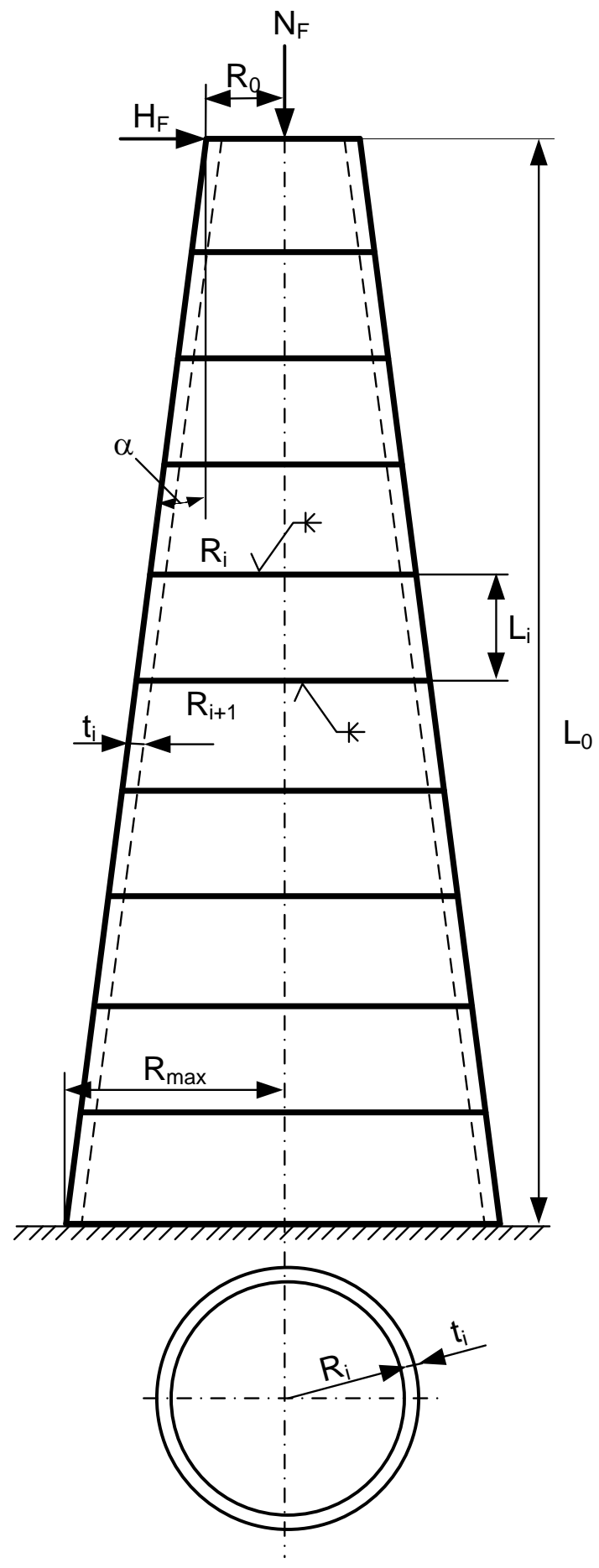

Fig. 1 Conical shell cantilever column loaded by axial compression and bending

The thickness, the average radius and the length of the $i^{\text {th }}$ equivalent shell part are

$$
t_{e i}=t_{i} \cos \alpha, R_{e a i}=\frac{R_{i}+R_{i+1}}{2 \cos \alpha}, \quad L_{e i}=\frac{L_{i}}{\cos \alpha},
$$


The inclination angle is defined by

$$
\tan \alpha=\frac{R_{\max }-R_{0}}{L_{0}}
$$

The sum of the axial and bending stresses should be smaller than the critical buckling stress

$$
\sigma_{a i}+\sigma_{b i}=\frac{N_{F}}{2 R_{i} \pi t_{e i}}+\frac{H_{F}\left(\sum_{j=0}^{i-1} L_{j}+\frac{L_{i}}{2}\right)}{R_{i}^{2} \pi t_{e i}} \leq \sigma_{c r i}=\frac{f_{y}}{\sqrt{1+\lambda_{i}^{4}}}
$$

where the reduced slenderness

$$
\lambda_{i}^{2}=\frac{f_{y}}{\sigma_{a i}+\sigma_{b i}}\left(\frac{\sigma_{a i}}{\sigma_{E a i}}+\frac{\sigma_{b i}}{\sigma_{E b i}}\right)
$$

The elastic buckling stress for the axial compression is

$$
\begin{aligned}
& \sigma_{E a i}=C_{a i}(1.5-50 \beta) \frac{\pi^{2} E}{10.92}\left(\frac{t_{e i}}{L_{e i}}\right)^{2} \\
& C_{a i}=\sqrt{1+\left(\rho_{a i} \xi_{i}\right)^{2}}, \rho_{a i}=0.5\left(1+\frac{R_{e a i}}{150 t_{e i}}\right)^{-0.5} \\
& \xi_{i}=0.702 Z_{i}, Z_{i}=\frac{L_{e i}^{2} \sqrt{1-v^{2}}}{R_{e a i} t_{e i}}, v=0.3
\end{aligned}
$$

The elastic buckling stress for bending is

$$
\sigma_{E b i}=C_{b i}(1.5-50 \beta) \frac{\pi^{2} E}{10.92}\left(\frac{t_{e i}}{L_{e i}}\right)^{2}
$$




$$
C_{b i}=\sqrt{1+\left(\rho_{b i} \xi_{i}\right)^{2}}, \rho_{b i}=0.5\left(1+\frac{R_{e a i}}{300 t_{e i}}\right)^{-0.5}
$$

Note that the residual welding distortion factor $1.5-50 \beta=1$ when $t>9 \mathrm{~mm}$. The detailed derivation of it is treated in (Farkas and Jármai 2003).

\section{The cost function}

The cost function contains the cost of material, forming of plate parts to conical or circular shell elements, welding and painting and is formulated according to the fabrication sequence.

The material cost is given by

$$
\begin{aligned}
& K_{M}=k_{M} \rho V, k_{M}=1.0 \$ / \mathrm{kg} \cdot \rho=7.85 \times 10^{-6} \\
& V=2 \pi \sum_{i=1}^{10} R_{e a i} L_{e i} t_{i}
\end{aligned}
$$

The cost of forming of plate parts into conical or circular shell elements

$$
\begin{aligned}
& K_{F}=k_{F} \Theta \sum_{i=1}^{10} e^{\mu_{i}}, \\
& \mu_{i}=6.8582513-4.52721 t_{i}^{-0.5}+0.009531996\left(2 R_{\text {eai }}\right)^{0.5}
\end{aligned}
$$

The coefficient for the complexity of assembly is $\Theta=3$. The specific fabrication cost factor is taken as $k_{F}=1.0 \$ / \mathrm{min}$.

For a shell element 3 axial butt welds are needed (GMAW-C - Gas Metal Arc Welding with $\mathrm{CO}_{2}$ )

$$
K_{W 0 i}=k_{F}\left(\Theta \sqrt{\kappa \rho V_{i}}+1.3 \times 0.152 \times 10^{-3} t_{i}^{1.94} 3 L_{e i}\right)
$$


The number of assembled elements is $\kappa=3$.

Cost of welding of circumferential welds between shell elements. The welding is performed successively, so one weld is connecting only two parts in each fabrication step.

$$
K_{W i}=k_{F}\left(\Theta \sqrt{2 \rho\left(\sum_{j=1}^{i-1} V_{j}+V_{i}\right)}+1.3 \times 0.152 \times 10^{-3} t_{i}^{1.94} 2 \pi R_{i}\right)
$$

Cost of painting

$$
K_{P}=k_{P} 4 \pi \frac{R_{\max }+R_{0}}{2} L_{0}, k_{P}=28.8 \times 10^{-6} \$ / \mathrm{mm}^{2}
$$

The total cost

$$
K=K_{M}+K_{F}+\sum_{i=1}^{10} K_{W 0 i}+\sum_{i=1}^{10} K_{W i}+K_{P}
$$

\section{Numerical data and results}

$L_{0}=15 \mathrm{~m}$, this height is divided in 10 shell parts, each length of $L_{i}=1500 \mathrm{~mm}$. This uniform length is selected for easy fabrication. $N_{F}=3400 \mathrm{kN}, H_{F}=0.1 N_{F}, f_{y}=355 \mathrm{MPa}, E=$ $2.1 \times 10^{5} \mathrm{MPa}$.

The calculation is performed by using a MathCAD algorithm. Results are given in Tables 1,2 and 3.

Table 1 Cost parts (\$) of conical shells of inclination angle $2.86^{\circ}$ for different radii (mm)

\begin{tabular}{cccccccc}
\hline$R_{0}$ & $R_{\max }$ & $K_{M}$ & $K_{F 0}$ & $K_{W 0}$ & $K_{W}$ & $K_{P}$ & $K$ \\
\hline 750 & 1500 & 26300 & 19895 & 9702 & 14750 & 6107 & 76754 \\
\hline 850 & 1600 & 25660 & 19360 & 8300 & 13753 & 6650 & 73723 \\
\hline 1050 & 1800 & $\mathbf{2 4 7 5 0}$ & 18492 & 6536 & 12300 & 7736 & 69814 \\
\hline
\end{tabular}




\begin{tabular}{llllllll}
\hline 1250 & 2000 & 24790 & 17974 & 5664 & 11796 & 8822 & $\mathbf{6 9 0 4 6}$ \\
\hline 1450 & 2200 & 25320 & 17709 & 5191 & 11640 & 9907 & 69767 \\
\hline 1650 & 2400 & 26090 & 17565 & 4881 & 11754 & 10990 & 71280 \\
\hline
\end{tabular}

In Table 1 the minimum material cost (volume) and total cost are marked by bold letters. It can be seen that the minimum volume and minimum cost correspond to different radii. This difference is caused by high fabrication costs. The optimum is found, since the decrease of radii causes increase of thicknesses, which increases the material and welding cost, on the other hand the increase of radii causes increase of material and painting cost.

Table 2 Cost parts (\$) of conical shells of different inclination angles (the average radius is $1625 \mathrm{~mm}$ )

\begin{tabular}{ccccccccc}
\hline Angle & $R_{0}$ & $R_{\max }$ & $K_{M}$ & $K_{F 0}$ & $K_{W 0}$ & $K_{W}$ & $K_{P}$ & $K$ \\
\hline $4.38^{0}$ & 1050 & 2200 & 24870 & 17961 & 5676 & 11582 & 8822 & $\mathbf{6 8 9 1 1}$ \\
\hline $6.65^{0}$ & 750 & 2500 & 25160 & 18246 & 5920 & 11424 & 8822 & 69572 \\
\hline
\end{tabular}

The thicknesses for the optimal conical shell of inclination angle $4.38^{0}$ are from above as follows: 18, 19, 20 and all others $21 \mathrm{~mm}$.

Table 3 Cost parts (\$) of circular shells for different radii. The minimum cost is marked by bold letters

\begin{tabular}{ccccccc}
\hline$R_{0}=R_{\max }$ & $K_{M}$ & $K_{F 0}$ & $K_{W 0}$ & $K_{W}$ & $K_{P}$ & $K$ \\
\hline 1450 & 25750 & 18661 & 7070 & 13640 & 7872 & 72993 \\
\hline 1650 & 25500 & 17960 & 5825 & 12393 & 8957 & $\mathbf{7 0 6 3 5}$ \\
\hline 1750 & 25500 & 17920 & 5596 & 12385 & 9500 & 70901 \\
\hline 1850 & 25730 & 17809 & 5333 & 12250 & 10040 & 71162
\end{tabular}

The thicknesses for the optimal circular shell of radius $1650 \mathrm{~mm}$ are as follows: $14,15,17$, $18,20,21,23,24,26$ and $27 \mathrm{~mm}$. 


\section{Conclusions}

The following fabrication aspects are considered: the change of shell thickness is designed in equal distances, the circumferential welds are welded successively to ease the welding inside of the shell, only integer numbers are used for shell thicknesses.

The structural volume or components of cost vary with radii in such manner that for both circular or conical unstiffened shells optimum radius can be found.

Three inclination angles of conical shell have been investigated and one of them was optimal.

The comparison of conical and circular shells shows that the cost of optimal conical shell is lower than that of circular one, but the difference is not very large (70635$68911) / 70635 \times 100=2.8 \%$.

\section{Acknowledgement}

The research was supported by the TÁMOP 4.2.4.A/2-11-1-2012-0001 priority project entitled 'National Excellence Program - Development and operation of domestic personnel support system for students and researchers, implemented within the framework of a convergence program, supported by the European Union, co-financed by the European Social Fund. The research was supported also by the Hungarian Scientific Research Fund OTKA T 109860 project and was partially carried out in the framework of the Center of Excellence of Innovative Engineering Design and Technologies at the University of Miskolc.

\section{References}

Det Norske Veritas (2002) Buckling strength of shells. Recommended Practice DNV-RPC202. Høvik, Norway

Eurocode 3 (2009) Design of steel structures. Part 1-1: General structural rules. Brussels, CEN

Farkas J, Jármai K (1997) Analysis and optimum design of metal structures, Rotterdam, Brookfield, Balkema 
Farkas J, Jármai K (2003) Economic design of metal structures, Rotterdam, Millpress

Farkas J, Jármai K (2008a) Design and optimization of metal structures, Chichester, UK, Horwood Publishing

Farkas,J.,Jármai,K. (2008b) Minimum cost design of a conical shell - External pressure, nonequidistant stiffening. In „Eurosteel 2008 5th European Conference on Steel and Composite Structures Graz Austria. Proceedings Ofner,R. et al. eds.Brussels, ECCS European Convention for Constructional Steelwork, 2008”.Vol.B. 1539-1544.

Ghazijahani Tohid Ghanbari, Showkati Hossein (2011) Experiments on conical shell reducers under uniform external pressure. J Constr Steel Res 67: 1506-1515

Harding JE (1981) Ring-stiffened cylinders under axial and external pressure loading. Proc. Inst Civ. Engrs Part 2. 71:(Sept.) 863-78

Huang J, Wierzbicki T (1993) Plastic tripping of ring stiffeners. J. Struct. Eng Proc Am Soc Civ Eng 119: (5) 1622-42

Pappas M, Allentuch A (1974) Extended capability for automate design of frame-stiffened submersible cylindrical shells. Comput. Struct. 4: (5) 1025-59

Pappas M, Morandi J (1980) Optimal design of ring-stiffened cylindrical shells using multiple stiffener sizes. AIAA J 18: (8) 1020-22

Tian J, Wang CM, Swaddiwudhipong S (1999) Elastic buckling analysis of ring-stiffened cylindrical shells under general pressure loading via the Ritz method. Thin-Walled Struct. 35: $1-24$

Wang CM, Swaddiwudhipong S, Tian J (1997) Buckling of cylindrical shells with general ring-stiffeners and lateral pressure distributions. In: Proceedings of the Seventh Internat. Conf. Computing in Civil and Building Engng. Vol.1. Eds. Choi ChK et al. Seoul, Korea 237-42 